\title{
Prevalence of acute deep vein thrombosis according to HIV status following major orthopaedic surgery at the University Teaching Hospital, Lusaka, Zambia
}

\author{
Collin West, Yakub Mulla, James Munthali \\ Department of Surgery, University of Zambia, University Teaching Hospital, Lusaka, Zambia \\ Correspondence: Dr Collin West (colinpeterwest@gmail.com)
}

(c) 2018 C. West et al. This open access article is licensed under a Creative Commons Attribution 4.0 International License (http://creativecommons.org/licenses/by/4.0/) which permits unrestricted use, distribution, and reproduction in any medium, provided you give appropriate credit to the original author(s) and the source, provide a link to the Creative Commons license, and indicate if changes were made.

East Cent Afr J Surg. 2018 Dec;23(3):104-108 https://dx.doi.org/10.4314/ecajs.v23i3.4

\begin{abstract}
Background

Hypercoagulable states and immobilization following lower limb, pelvic, and spinal surgery increases the risk of deep vein thrombosis (DVT). It is also suggested that HIV alone increases the risk of deep vein thrombosis. However no study has been done to determine the prevalence of deep vein thrombosis in HIV seropositive individuals who have undergone lower limb orthopaedic surgery in the Zambian context. We therefore conducted this study to determine the prevalence of deep vein thrombosis in patients who are HIV seropositive in comparison to those who are HIV seronegative after undergoing lower limb orthopaedic surgery.

\section{Methods}

A total of 42 Patients were enrolled. Of these 23 (54\%) were HIV negative controls and 19 (46\%) were HIV positive patients who underwent lower limb surgery or spinal surgery. Demographic and HIV status data was collected prior to surgery. After surgery a blood sample was tested for fibrinogen degradation products (D-dimer) levels. The patients were then monitored for the development of clinical DVT and those that developed clinical DVT had an ultrasound to confirm the diagnosis.

\section{Results}

The majority (81\%) of the study population were under the age of 50 years. The mean values of D-dimers were $2.33 \pm 1.65 \mu \mathrm{g} / \mathrm{ml}$ for the HIV negative group and $2.55 \pm 1.50 \mathrm{\mu g} / \mathrm{ml}$ for the HIV positive group. The number of positive D-dimer results was similar in the two groups, $94.7 \%$ for the HIV cohort and $95.7 \%$ in the negative group ( $X 20.19 p=0.89$ ). There was a positive correlation between the D-dimer value and the type of surgery done in both the HIV positive group $(R 0.390 p=0.049)$ and the HIV negative group (R 0.398 at $p=0.03$ ). In both group's hip and knee surgeries gave higher values of $D$-dimers. There was no statistical difference in the occurrence of a positive D-dimer and CD4 count (X2 $0.95 \mathrm{p}=0.89)$. The combined prevalence of clinical DVT confirmed by compression ultrasonography in the entire study population was 4.8\%. The prevalence in the HIV seropositive group and HIV seronegative groups were $5.3 \%$ and $4.3 \%$ respectively ( X2 $0.19 p=0.89$ ). None of the patients received preoperative DVT prophylaxis due to cost but both patients that developed DVT received antithrombotic treatment.
\end{abstract}

\section{Conclusions}

There was no significant difference in the prevalence of DVT between patients who were HIV seronegative and seronegative following major lower limb and spinal orthopaedic surgery. Both groups had raised D-dimer values.

Keywords: deep vein thrombosis, HIV, D-dimer, Doppler ultrasound

\section{Introduction}

Patients presenting to our health services with orthopaedic conditions who are HIV seropositive are expected to increase as their life expectancy improves. The UNAIDS report (2013) estimates 4.2 million people aged 50 and older were living with HIV of which 2.5 million people live in sub-Saharan Africa, accounting for $60 \%$ this population. ${ }^{1}$ In a study by Berman et al (1998) they found that $71 \%(n=101)$ of HIV positive patients had musculoskeletal manifestations during the course of their disease caused by the HIV infection, HIV treatment or both HIV infection and its treatment. ${ }^{2}$ In addition, a study by Mundama et al of 296 medical patients, who were ambulatory and had no major risk factor for DVT, at the University Teaching Hospital found that proximal lower limb DVT was common among HIV positive medical patients admitted for at least 7 days. ${ }^{3}$ 
Table 1: Inclusion and Exclusion Criteria for Enrolment into the Study

\begin{tabular}{|l|l|}
\hline Inclusion Criteria: & Exclusion Criteria \\
\hline Age 21 years or above, Male or Female & Patients with known malignancies \\
\hline $\begin{array}{l}\text { Planned for elective major lower limb and spinal orthopaedic } \\
\text { surgery: Intramedullary Nailing, Total and Partial Hip } \\
\text { of Fractures, Open Join reduction, Arthrodesis, and } \\
\text { sequestrectomies }\end{array}$ & Patients on hormone replacement therapy \\
\hline Irrespective of HIV status & Patients on pro-coagulant therapy \\
\hline Any CD4 Count & Patients with prior history of DVT or PE \\
\hline On ART or not & Patients who are pregnant \\
\hline
\end{tabular}

Lower limb orthopaedic surgery like hip and knee surgery is known to predispose patients to deep vein thrombosis. ${ }^{4}$ The prevalence of asymptomatic DVT in patients with pelvic, femoral and tibia/fibula fractures at the University Teaching Hospital Lusaka, was found to be $10.8 \%$ following trauma. ${ }^{5}$ The incidence of asymptomatic DVT following a major orthopaedic surgery without prophylaxis reportedly ranges from $30 \%$ to $80 \%$, whereas the incidence of symptomatic DVT reportedly ranges from $0.5 \%$ to $4 \%{ }^{6}$

Various abnormalities predisposing to a hyper-coagulable state have been reported in AIDS patients including the presence of antiphospholipid antibodies and the lupus anticoagulant; deficiencies of protein $\mathrm{C}$, protein $\mathrm{S}$, heparin cofactor II, and antithrombin and increased levels of von Willebrand factor, and d-dimers. ${ }^{7}$ These abnormalities correlate with the severity of HIV-associated immunosuppression as measured by the CD4 cell counts and with the presence of concurrent infectious or neoplastic diseases. ${ }^{8}$ With reports suggesting HIV alone increases the risk of deep vein thrombosis, ${ }^{3}$ it is prudent that this aspect of the clinical continuum of care for HIV positive individuals be investigated. This study thus aimed to measure the prevalence of deep vein thrombosis in patients who are HIV seropositive compared to those who are HIV seronegative both of whom are exposed to the major risk factor of orthopaedic surgery.

\section{Methods}

This was a cross sectional study conducted at the University Teaching Adult Hospital a tertiary level hospital in Lusaka Zambia which also serves as a National Referral Centre. The sample size was calculated using the prevalence formula and consecutive convenience sampling was done for those undergoing major limb and spinal orthopaedic surgery who met the inclusion criteria, as outlined in Table 1, were enrolled in the study.

The study did not interfere with treatment plans of the attending surgical teams but results of D-dimers and Doppler ultrasound were made available to the attending teams as DVT is a life threatening condition. Patients were free to opt-out anytime during the course of the study and any information collected from them was not used in the study unless expressed permission was given by the patient.

The D-dimer were tested using the VIDAS@ D-Dimer Exclusion $\mathrm{II}^{\circledR}$ which is an automated quantitative test for immune-enzymatic determination of fibrin degradation products in human plasma stored in sodium citrate using enzyme linked fluorescent assay with measurement range of $45 \mathrm{ng} / \mathrm{ml}$ to $10000 \mathrm{ng} / \mathrm{ml}$.

Ethical approval was granted by the University of Zambia Biomedical Research Ethics Committee prior to commencement and enrolment for the study. Written informed consent was obtained before any participants were enrolled by signature or witnessed thumb print.

\section{Results}

42 patients were enrolled in the study over a period of 4 months. Fifty-four percent of the patients $(n=23)$ were HIV negative and $46 \%(\mathrm{n}=19)$ were HIV positive. The gender distribution was $81 \%(n=34)$ male of which $41 \%(n=14)$ were HIV positive. Nineteen percent of the patients $(n=8)$ were female of whom $62 \%(n=5)$ were HIV positive.

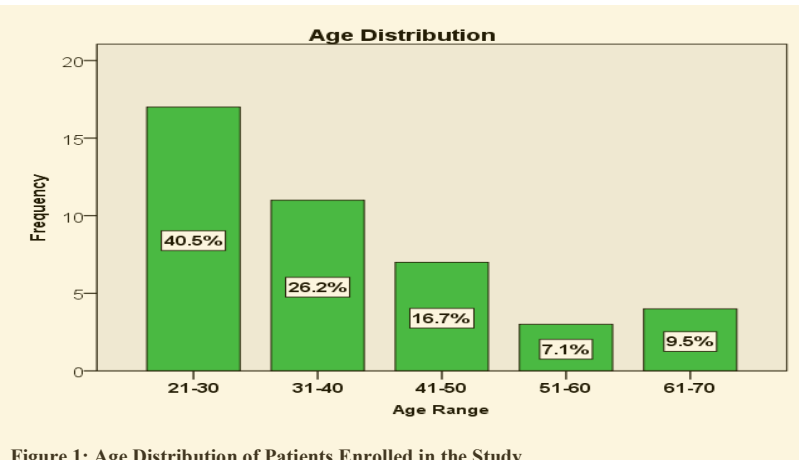

The majority ( $40.5 \%$ ) of the patients were between the ages of 21 and 30 with $82 \%$ of the total population being below the age of 50 years

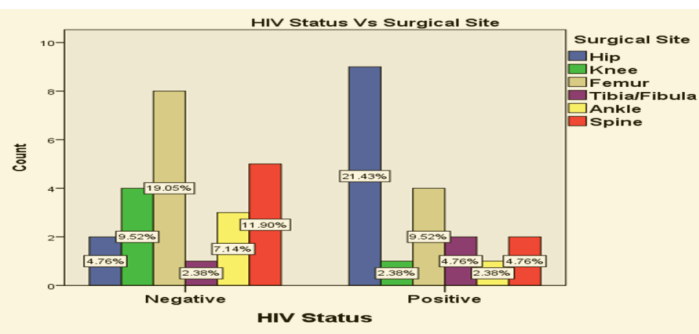

Figure 2: Surgical site Distribution in each cohort:

Intra-medullary Nailing (4 HIV +ve, 8 HIV -ve) $\mathrm{n}=12$, Hip Replacements( HIV +ve 9 , HIV -ve 2) n=11, Knee Replacement(2 HIV -ve) n=2, Plating and Screw Fixation of Fractures Knee ( 1 HIV +ve, 2 HIV -ve) n=3, Tibia ORIF (2 HIV +ve, 1 HIV -ve) n=3, Arthrodesis Ankle (1 HIV +ve, 3 HIV -ve) $n=4$ and Spine ( 2 HIV +ve, 5 HIV -ve) $n=7$. 
Table 2: Cross Tabulation of HIV status and clinical DVT

\begin{tabular}{|c|c|c|c|c|c|}
\hline & & & \multicolumn{2}{|c|}{$\begin{array}{l}\text { Did the patient develop any clinical } \\
\text { signs of DVT? }\end{array}$} & \multirow[b]{2}{*}{ Total } \\
\hline & & & No & Yes & \\
\hline \multirow{4}{*}{$\begin{array}{l}\text { What is the HIV Status in the } \\
\text { last } 3 \text { Months }\end{array}$} & Negative & Count & 22 & 1 & 23 \\
\hline & & Expected Count & 21.9 & 1.1 & 23.0 \\
\hline & Positive & Count & 18 & 1 & 19 \\
\hline & & Expected Count & 18.1 & .9 & 19.0 \\
\hline \multirow[t]{2}{*}{ Total } & & Count & 40 & 2 & 42 \\
\hline & & Expected Count & 40.0 & 2.0 & 42.0 \\
\hline
\end{tabular}

Only 1 patient in each of the cohorts developed clinical and ultra sound confirmed DVT which gave a prevalence of $5.3 \%$ in the HIV positive group and $4.3 \%$ in the control arm who were HIV negative. The chi-square test was employed to test if there was a significant difference in the occurrence of clinical DVT in the two groups and it was found that there was no difference at X2 $0.019 \mathrm{p}=0.890$. Significance was further tested using the Mantel - Haenzsel test and still found to $\mathrm{X} 20.339 \mathrm{p}=0.560$

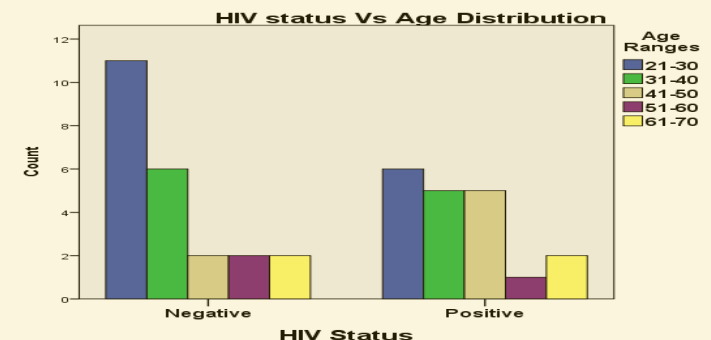

Figure 3: HIV Status according to age distribution

In both cohorts the majority of the patients were below the age of 50

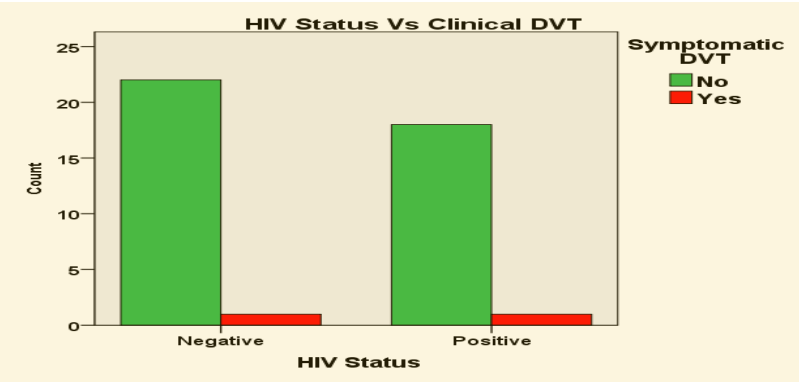

Figure 4: Number of patients that developed symptomatic DVT

One patient in each group developed Clinical DVT confirmed by Doppler Ultrasonography that is 1 of the 23 for the HIV negative group and 1 of 19 for the HIV positive group

The majority $(40.5 \%)$ of the patients were between the ages of 21 and 30 with $82 \%$ of the total population being below the age of 50 years (Figure 1).

The prevalence of positive $\mathrm{D}$-dimer test was $94.7 \%(\mathrm{n}=19)$ for the HIV positive group and $95.6 \%(n=22)$ for the HIV negative group. The Pearson Chi Square was applied gave $\mathrm{X} 2=0.19 \mathrm{p}=0.890$ meaning there was no significant difference between the two groups. As with the DVT comparisons this means that there was no difference in the occurrence of a positive D-dimer value whether HIV positive or negative. Ninety-five percent of all the study patients received early mobilization in form of active or passive physiotherapy. None receiving pre-operative pharmaco-prophylaxis

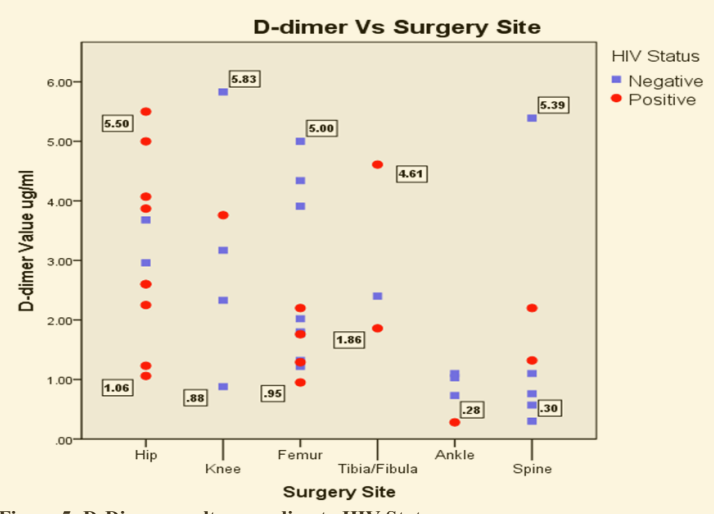

Figure 5: D-Dimer results according to HIV Status

There is a positive correlation between the type of surgery done and increasing value of the D-dimers that is the more proximal the surgery was the higher the value of the D-dimer. For the HIV positive cohort the $\mathrm{R}=+0.390, \mathrm{p}=0.049$ and $\mathrm{R}=+0.398 \mathrm{p}=0.03$ for the control

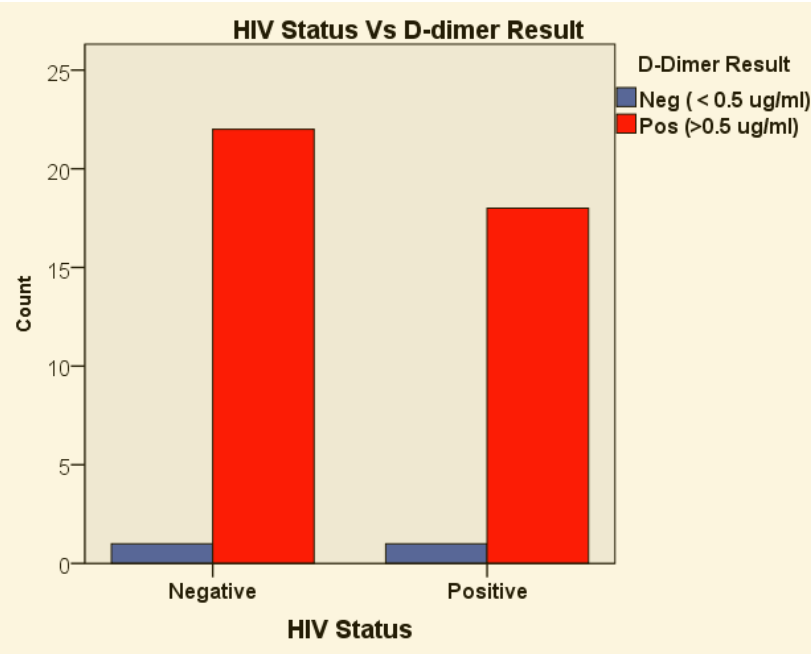

Figure 6: HIV Status against D-dimer Result 
Table 3: Summary of statistics

\begin{tabular}{|c|c|c|}
\hline Statistics & $H I V(+)$ & $H I V(-)$ \\
\hline Mean D-dimer: & $\begin{array}{lll}\mathbf{2 . 5 5} & +/- & 1.50 \\
\mu \mathrm{g} / \mathrm{ml} & & \end{array}$ & $\mathbf{2 . 3 3}+/-1.65 \mu \mathrm{g} / \mathrm{ml}$ \\
\hline $\begin{array}{l}\text { Prevalence }- \text { D-dimer } \\
\text { Positive }\end{array}$ & $94.7 \%$ & $95.7 \%\left(X^{2} 0.019 p=0.89\right)$ \\
\hline $\begin{array}{l}\text { Correlation of D dimer value } \\
\text { Vs Surgery Site }\end{array}$ & $\begin{array}{l}\mathrm{R}+0.390 \quad p= \\
0.049\end{array}$ & $\mathrm{R}+0.398 p=0.03$ \\
\hline $\begin{array}{l}\text { Prevalence of Clinical DVT: } \\
\text { No difference }\end{array}$ & $5.3 \%$ & $4.3 \%\left(X^{2} 0.019 p=0.89\right)$ \\
\hline \multicolumn{3}{|c|}{$\begin{array}{l}\text { No difference in D-dimer Positive Result among } \mathrm{CD}_{4} \text { count ranges }\left(\begin{array}{ll}X^{2} & 2.95 \\
(\mathrm{p}=0.89)\end{array}\right.\end{array}$} \\
\hline $\mathrm{CD}_{4}$ Count Ranges & $200-500 \mathrm{cell} / \mathrm{ul}$ & $>500$ cells/ul \\
\hline D-dimer Range & $1.06-5.50 \mathrm{ug} / \mathrm{ml}$ & $1.23-3.80 \mathrm{ug} / \mathrm{ml}$ \\
\hline
\end{tabular}

which was narrow at $3 \mathrm{ug} / \mathrm{ml}$ to $3.8 \mathrm{ug} / \mathrm{ml}$. The situation was reversed with those that had femur surgery in which in the control group $(n=8)$ range was wide from $1.2 \mathrm{ug} /$ $\mathrm{ml}$ to $5.0 \mathrm{ug} / \mathrm{ml}$ compared to the exposed group $(n=4)$ whose range was narrow at $1 \mathrm{ug} / \mathrm{ml}$ to $2.2 \mathrm{ug} / \mathrm{ml}$. This suggests that the patient distribution should have been matched according to types of surgery so as to get balances comparison of the ranges of the D-dimer values. These values were still lower than those found by Nkhoma et al whom compared D-dimers, IL-6, CD4, triglycerides and cholesterol of individuals admitted in the medical ward who were HIV positive on ART, HIV positive ART- naïve and HIV negative control partic-

\section{Discussion}

Venous thrombo-embolism (VTE) is a physiological derangement resulting in a pathological thrombus or clot formation in the deep venous system. ${ }^{9}$ Venous thrombosis, comprising deep vein thrombosis and pulmonary embolism, occurs with an incidence of approximately 1 per 1000 annually in adult populations. ${ }^{10}$ Rates are slightly higher in men than women, male-to-female ratio is 1.2:1. ${ }^{11}$ The gender distribution was skewed towards the male gender at $81 \%$. A similar to trend was seen in a study to determine the prevalence of Trauma cases and adoption of the Kampala Trauma Score at the University Teaching Hospital by Brown et al in which males age younger than 50 years made up the majority of trauma. ${ }^{12}$

The prevalence of a positive D-dimer test result $(>0.5 \mathrm{ug} /$ $\mathrm{ml}$ ) was $94.7 \%$ for the exposed group and $95.6 \%$ for the control group with no significant difference in the two groups. D-dimer values are expected to be high following surgery as a result of the fibrinolysis of the clots that occurs following tissue dissection. This increased levels of circulating degradation products places the patient in a hypercoagulable state. ${ }^{9}$ High D-dimer level greater than $2.0 \mu \mathrm{g} / \mathrm{ml}$ showed $68 \%$ sensitivity, $55 \%$ specificity, $60 \%$ accuracy, $50 \%$ positive predictive rate and $72 \%$ negative predictive rate in the detection of early DVT after total knee arthroplasty. ${ }^{13}$ Positive D-dimer values obtained in our study ranged from $0.57 \mathrm{ug} /$ $\mathrm{ml}$ to $5.39 \mathrm{ug} / \mathrm{ml}$ in general. The mean values of the two study groups were similar with $2.33+/-1.65 \mathrm{ug} / \mathrm{ml}$ for those in the control and $2.55+/-1.50 \mathrm{ug} / \mathrm{ml}$ for those in the HIV positive group. Those that were HIV positive and underwent hip surgery $(n=9)$ the $D$-dimer values had a wide distribution from $1 \mathrm{ug} / \mathrm{ml}$ to $5.37 \mathrm{ug} / \mathrm{ml}$ compared to the control group $(\mathrm{n}=2)$ ipants. His results showed that HIV ART naïve participants had higher $\mathrm{D}$-dimer $(0.794 \pm 0.318 \mathrm{ug} / \mathrm{ml})$ than those on ART $(0.514 \pm 0.187 \mathrm{ug} / \mathrm{ml}) \mathrm{p}=0.004$ and the HIV negative control participants $(0.375 \pm 0.165 \mathrm{ug} / \mathrm{ml}) \mathrm{p}=0.001 .^{14}$ Thus the surgery done these individuals seems to increase both groups' chances of developing DVT and overrides their increase risk of DVT shown by the studies done on the medical patients.

Significant correlation was found between the D-dimer value and the type of surgery done, with the HIV positive group giving an $\mathrm{R}+0.390(\mathrm{p}=0.049)$ and that of the control was $R+0.398(p=0.03)$. The hip, knee and femur surgeries had more $\mathrm{D}$-dimer values clustered above value of $2 \mathrm{ug} / \mathrm{ml}$ as compared to that of the tibia, ankle and spine surgeries whose clusters were below $2 \mathrm{ug} / \mathrm{ml}$. This is consistent with risk rating for hip and knee arthroplasty as a high risk for development of DVT. ${ }^{6}$ That is the proximal limb surgeries gave higher values of $\mathrm{D}$-dimer than that of distal limb surgeries. The proximal limb up to the knee involved more tissue dissection and intimal blood vessel injury than the distal limb and spine surgeries due to limb manipulations. ${ }^{15}$

Anecdotal evidence form surgical experience in our hospital suggested that the prevalence of DVT among our post-operative patients was generally low and that the numbers reported in the Europe and North American literature were much higher than that would be seen in our local population. The recent studies done by Mundama et al in medical patients and Chibeza et al on trauma patients which showed DVT prevalence of $11.1 \%$ and $10.8 \%$, respectively. When broken down their prevalence of symptomatic DVT $1.7 \%$ for the medical patients and $1.4 \%$ for the trauma patients. ${ }^{5}$ In our finding the prevalence of $4.8 \%$ of symptomatic DVT 
was found. A study by Jacobson et al (2004) of thrombotic complications in patients infected with HIV in the era of highly active antiretroviral therapy found 30 of 650 outpatients developed a total of 43 venous or arterial thrombosis during 1996-2002. ${ }^{16}$ The prevalence of DVT in HIV positive and control cohorts of our study were $5.3 \%$ and $4.3 \%$ respectively with statistically no significant difference between the two (X2 $0.19 \mathrm{p}=0.89)$. When compared with the prevalence of $(1.7 \%)$ for symptomatic DVT in the medical wards, the prevalence in both cohorts was higher. This implies that an HIV positive patient who has undergone lower limb surgery is 3.11 times more likely to develop DVT than an HIV positive patient admitted to the medical ward. Both patients that developed DVT were above the age of 60 years, with the HIV positive individual having undergone hip surgery and the control having had femur shaft surgery with both surgeries taking between 2-3 hours of operating time. Thus both individuals had similar operating times and were of an elderly age group. Thus both were high risk patients for developing DVT, ${ }^{4}$ and should have received chemoprophylaxis but due to financial constraints of both the hospital and patients did not, but both went on to be treated with anti-thrombotic therapy as per protocol which was provided free by the hospital. Here lies another financial debate for resource constraint intuitions like ours. Would it be cheaper to just provide treatment for DVT rather than prophylaxis?

Despite not receiving post-operative pharmacoprophylaxis and having positive post-operative positive D-dimers values that were high, only one in each group developed symptomatic DVT. Arguably there would have been more patients that would have had subclinical DVT given the trends of the studies done by Mwandama et al and Chibeza et al had we looked for them. Asymptomatic DVT management still remains an area of debate as whether to treat as one would treat symptomatic DVT or manage these patients on the prophylactic dose of chemotherapy.

Mechanical prophylaxis, which include graduated compression stockings alone can half the rates of DVT. ${ }^{17}$ Ninety-five percent of all the study patients received early mobilization in form of active or passive physiotherapy. This may be the may be the reason why they did not go on to develop clinical DVT despite having high D-dimer values. Our robust early mobilization post-operative policy which is implemented with the help of qualified physiotherapy team is an invaluable asset in both prevention of post-operative morbidity like DVT and PE as well as improving functional outcomes of our patients.

In an attempt to have representative sample of the population that present to our study site for elective surgery, D-dimer tests were not done pre operatively as this was not a standard pre-operative test at our site and may have led to exclusion of patients who would have normally undergone surgery. This is a limitation of the study as cannot conclusively rule out that the high D-dimer levels postoperatively were not present pre operatively.

\section{Conclusions}

The study showed that the prevalence of post-operative orthopedic lower limb surgery-related clinical DVT was found to be $5.3 \%$. Furthermore there was no difference in the prevalence of DVT in HIV positive and HIV negative patients following lower limb surgery and spinal surgery at the University Teaching Hospital in Lusaka.

\section{Competing interests}

All authors declare that they have no competing interests related to this work.

\section{References}

1. UNAIDS, "UNAIDS," 2015. [Online]. Available: http://www.unaids. org/en/regionscountries/countries/zambia. [Accessed 12 February 2015].

2. Berman, "Rheumatic manifestations of human immunodeficiency virus infection," American Journal of Medicine, vol. 85, pp. 59-64, 1998 Jun.

3. Mwandama, "Prevalence of Deep Vein Thrombosis and Associated Factors in Adult Medical Patients admitted to the University Teaching Hospital, Lusaka, Zambia," Medical Journal of Zambia," vol. 43, no. 4, pp. 224 - 230, 2016.

4. Geerts WH, "Prevention of venous thromboembolism: American College of Chest Physicians evidence based clinical practice guidelines (8th edition). Chest 2008;133(6Suppl):381S-453S.)," Chest, vol. 133, no. 6, pp. 381S-453S, 2008

5. Chibeza, "prospective study to determine the prevalence of DVT in patients with pelvic, femoral and tibia/fibula fractures at the University Teaching Hospital Lusaka,"UNZA Press, Lusaka, 2015.

6. Falck-Ytter, "Prevention of VTE in orthopedic surgery patients: Antithrombotic Therapy and Prevention of Thrombosis9th ed: American College of Chest Physicians Evidence-Based Clinical Practice Guidelines.," Chest, vol. 141, no. (2 Suppl), pp. e278S-325S, 2012

7. Crum-Cianflone, "Thromboses among HIV-Infected Patients during the Highly Active Antiretroviral Therapy Era," AIDS PATIENT CARE and STDs, vol. Volume 22, no. Number 10, pp. 771-781, 2008

8. Saif, "HIV and thrombosis: a review.," AIDS Patient Care STDS, vol. 15, no. 1, pp. 15-24, 2001 Jan

9. Kumar, Robbins and Cotran, Pathologic Basis of Disease, 7th ed. Philadelphia: Elsevier Saunders, 2005.

10. Cushman, "Epidemiology and Risk Factors for Venous Thrombosis," Semin Hematol, vol. 44, no. 2, p. 62-69, 2007

11. Patel, "Medscape," 28th August 2014. [Online]. Available: http:// emedicine.medscape.com/article/1911303-overview\#showall. [Accessed 9th May 2015]

12. Oramore-Brown, "A Study to Determine the Prevalence of Trauma Cases and Adoption of the Kampala Trauma score at the University Teaching Hospital, Lusaka," UNZA press, Lusaka, 2013.

13. Chung-Jen Chen, "The value of D-dimer in the detection of early deep-vein thrombosis after total knee arthroplasty in Asian patients: a cohort study,"Thrombosis Journal, vol. 6, no. 5, 2008.

14. Nkhoma, "Assessment of D-Dimer and IL-6 levels in HIV positive individuals at the University Teaching Hospital, Lusaka,"UNZA press, Lusaka, 2015

15. Raftery, Basic Science, 2nd ed., Philadelphia: Elsevier, 2008.

16. Jacobson, "Thrombotic Complications in Patients Infected with HIV in the Era of Highly Active Antiretroviral Therapy: A Case Series," Clinical Infectious Diseases, vol. 39, no. 8, pp. 1214-1222, 2004.

17. Prandoni P,"Below-knee elastic compression stockings to prevent the postthrombotic syndrome: a randomized, controlled trial,"Ann Intern Med, 2004 